ASTHMA

\title{
Genome-wide linkage analysis of pulmonary function in families of children with asthma in Costa Rica
}

\author{
Craig P Hersh, Manuel E Soto-Quirós, Lydiana Avila, Stephen L Lake, Catherine Liang, Eduardo \\ Fournier, Mitzi Spesny, Jody S Sylvia, Ross Lazarus, Thomas Hudson, Andrei Verner, Barbara \\ J Klanderman, Nelson B Freimer, Edwin K Silverman, Juan C Celedón
}

Thorax 2007;62:224-230. doi: 10.1136/thx.2006.067934

See end of article for authors' affiliations

Correspondence to: Dr J C Celedón, Channing Laboratory, Brigham and Women's Hospital, 181 Longwood Avenue, Boston, MA 02115, USA; juan. celedon@channing.harvard. edu

Received 29 June 2006 Accepted

27 September 2006

Published Online First

10 November 2006
Background: Although asthma is highly prevalent among certain Hispanic subgroups, genetic determinants of asthma and asthma-related traits have not been conclusively identified in Hispanic populations. A study was undertaken to identify genomic regions containing susceptibility loci for pulmonary function and bronchodilator responsiveness (BDR) in Costa Ricans.

Methods: Eight extended pedigrees were ascertained through schoolchildren with asthma in the Central Valley of Costa Rica. Short tandem repeat (STR) markers were genotyped throughout the genome at an average spacing of $8.2 \mathrm{cM}$. Multipoint variance component linkage analyses of forced expiratory volume in 1 second $\left(\mathrm{FEV}_{1}\right)$ and $\mathrm{FEV}_{1}$ / forced vital capacity (FVC; both pre-bronchodilator and post-bronchodilator) and $B D R$ were performed in these eight families (pre-bronchodilator spirometry, $n=640$; post-bronchodilator spirometry and BDR, $n=624$ ). Nine additional STR markers were genotyped on chromosome 7. Secondary analyses were repeated after stratification by cigarette smoking.

Results: Among all subjects, the highest logarithm of the odds of linkage (LOD) score for FEV 1 (postbronchodilator) was found on chromosome 7q34-35 (LOD $=2.45$, including the additional markers). The highest LOD scores for FEV 1 /FVC (pre-bronchodilator) and BDR were found on chromosomes $2 q$ $(L O D=1.53)$ and $9 p(L O D=1.53)$, respectively. Among former and current smokers there was nearsignificant evidence of linkage to $\mathrm{FEV}_{1} / \mathrm{FVC}$ (post-bronchodilator) on chromosome $5 p(L O D=3.27$ ) and suggestive evidence of linkage to $\mathrm{FEV}_{1}$ on chromosomes $3 q$ (pre-bronchodilator, $L O D=2.74$ ) and $4 q$ (postbronchodilator, $L O D=2.66$ ).

Conclusions: In eight families of children with asthma in Costa Rica, there is suggestive evidence of linkage to $\mathrm{FEV}_{1}$ on chromosome 7q34-35. In these families, FEV 1 /FVC may be influenced by an interaction between cigarette smoking and a locus (loci) on chromosome $5 p$.
S pirometric measurements of pulmonary function are important markers of asthma severity and critical intermediate phenotypes for asthma research. Several groups have identified genomic regions linked to pulmonary function measurements (such as forced expiratory volume in 1 second $\left(\mathrm{FEV}_{1}\right)$ and $\mathrm{FEV}_{1}$ / forced vital capacity (FVC) ratio) in families ascertained through probands with asthma. ${ }^{1-3}$ The prevalence and severity of asthma are markedly variable among different Hispanic populations living in the US and Latin America, and these differences may have an underlying genetic component. ${ }^{4}$ In the Collaborative Study on the Genetics of Asthma, ${ }^{5}$ genome-wide linkage analysis of asthma and some of its intermediate phenotypes (eg, total serum IgE) were performed in Hispanic families from New Mexico. However, there has been no genome-wide linkage analysis of pulmonary function phenotypes in any Hispanic population.

Bronchodilators, specifically $\beta_{2}$-adrenergic receptor agonists, are the most widely prescribed drugs in the treatment of asthma. There is a substantial inter-individual variation in the response to inhaled $\beta_{2}$-agonists, and bronchodilator responsiveness (BDR) has been shown to aggregate in families, ${ }^{6}$ consistent with a genetic component to the variation in BDR. Although multiple studies have examined genetic linkage for airway responsiveness to bronchoconstrictor agents or prebronchodilator and post-bronchodilator spirometry measurements, a genome-wide linkage analysis of BDR in families with asthma has not been published. The only reported linkage analysis for BDR was in families of probands with severe, earlyonset chronic obstructive disease (COPD). ${ }^{7}$

In this study, we performed genome-wide linkage analyses of pulmonary function measurements and BDR in families of children with asthma in Costa Rica, a nation with a high prevalence of childhood asthma. ${ }^{8}$ Most Costa Ricans live in the Central Valley, where there is a genetically isolated population of predominantly mixed Spanish and Amerindian origin.' Extensive genealogical records can be used to track the rapid expansion of this population from approximately 4000 founding individuals registered in the census of $1697^{10}$ to about 2.85 million current residents of the Central Valley. The unique characteristics of the population of the Central Valley make it ideal for studies of the genetics of asthma and/or its intermediate phenotypes.

\section{METHODS}

Study subjects

Seven probands were recruited through an ongoing study of children with asthma; an eighth proband was recruited from phase II of the International Study of Asthma and Allergies in Childhood in Costa Rica. ${ }^{11}$ Eligible probands were 6-12 years old and had physician-diagnosed asthma, $\geqslant 2$ respiratory

Abbreviations: $B D R$, bronchodilator responsiveness; COPD, chronic obstructive pulmonary disease; $\mathrm{FEV}_{1}$, forced expiratory volume in 1 second; FVC, forced vital capacity; LOD, logarithm of the odds of linkage; SOLAR, Sequential Oligogenic Linkage Analysis Routines; STR, short tandem repeat 
symptoms (cough, wheeze, or dyspnoea) or asthma attacks in the previous year, airway hyper-responsiveness (provocative dose of methacholine causing a $20 \%$ decline in $\mathrm{FEV}_{1}\left(\mathrm{PD}_{20}\right)$ $\leqslant 8.58 \mu \mathrm{mol}$ ), $\geqslant 1$ sibling with physician-diagnosed asthma, and $\geqslant 6$ great-grandparents born in the Central Valley of Costa Rica. All first-degree and second-degree relatives of the proband ( $\geqslant 6$ years old) were invited to participate. Families were further extended by including first-degree relatives of individuals with asthma.

All adults gave written informed consent; parental consent was obtained for participating children, who also gave written assent. The study was approved by the Institutional Review Boards of the Hospital Nacional de Niños, San José, Costa Rica and Brigham and Women's Hospital (BWH), Boston, Massachusetts.

\section{Phenotypic assessment}

Each study participant completed a questionnaire and spirometry and gave a blood sample for DNA extraction. The study questionnaire was modified from that used by the Collaborative Study on the Genetics of Asthma ${ }^{12}$ and translated into Spanish. Two versions of the questionnaire were used: one for adolescents and adults ( $>12$ years old) and one for children $(\leqslant 12$ years old). Pack-years of cigarette smoking were calculated by multiplying the number of years of smoking by the average number of cigarettes per day, divided by 20 to convert to packs. Children ( $\leqslant 12$ years old) were assumed to be nonsmokers.

Spirometry was performed using a Survey Tach Spirometer (Warren E Collins, Braintree, Massachusetts) according to the American Thoracic Society recommendations. ${ }^{13}$ Height was measured to the nearest half-inch. Spirometry was performed while subjects were seated and wearing a noseclip. Up to eight attempts were made to obtain three acceptable flow-volume loops. Participants were asked to refrain from use of shortacting bronchodilator drugs for at least 4 hours before testing. Spirometry was repeated $15 \mathrm{~min}$ after the administration of $200 \mu \mathrm{g}$ (two puffs) of albuterol through a spacer. The best FEV and FVC were selected for both pre-bronchodilator and postbronchodilator spirometry.

\section{Genotyping}

DNA was extracted from blood samples using Puregene Kits (Gentra Systems). A panel of 380 short tandem repeat (STR) markers was genotyped by the Genome Quebec Innovation Centre using Applied Biosystems (Foster City, California) 3700 and 3730 analysers on 671 family members. This marker panel is a modified version of the Cooperative Human Linkage Center Human Screening set $/ V .6^{14}$ that also includes selected Genethon markers. ${ }^{15}$ Marker locations were based on the deCODE map. ${ }^{16}$ Markers were located at an average spacing of $8.2 \mathrm{cM}$.

An additional nine STR markers on chromosome 7 were genotyped at Brigham and Women's Hospital: D7S2452, D7S2533, D7S500, D7S509, D7S495, D7S2505, D7S3044 and D7S2511. Primer sequences available in the National Center for Biotechnology Information's UniSTS database (http:// www.ncbi.nlm.nih.gov/) were used to design assays. Fluorescent-labelled and unlabelled primers were obtained from Invitrogen (Carlsbad, California) and Applied Biosystems. PCR product sizes were assessed on an Applied Biosystems 3100 instrument. GeneScan and GeneMapper V.3.7 software were used to assist with genotype determination, and calls were manually reviewed.

Pedigree relationships were assessed by Relpair ${ }^{17}$; four subjects that did not match reported relationships were excluded from analysis. Mendelian inconsistencies at individual markers for the remaining 667 individuals were assessed using PedCheck. ${ }^{18}$

\section{Statistical analysis}

BDR was defined as: 1) BDRbase = change in $\mathrm{FEV}_{1}$ as a percentage of the baseline $\mathrm{FEV}_{1} ; 2$ ) $\mathrm{BDRpred}=$ change in $\mathrm{FEV}_{1}$ as a percentage of predicted $\mathrm{FEV}_{1}$; and 3) $\mathrm{BDRabs}=$ absolute change in $\mathrm{FEV}_{1}(\mathrm{ml}) .^{719}$ The three BDR measurements were normally distributed after $\log _{10}$ transformation.

Heritability estimation and multipoint linkage analysis of $\mathrm{FEV}_{1}, \mathrm{FEV}_{1} / \mathrm{FVC}$ and BDR measurements were performed by a variance component approach in Sequential Oligogenic Linkage Analysis Routines (SOLAR), which uses identity-by-descent sharing to estimate the additive genetic variance due to a chromosomal region. ${ }^{20}$ Results are expressed as logarithm of the odds of linkage (LOD) scores (logarithm [base 10] of the odds of linkage versus no linkage). Covariates included age, sex, height, weight, smoking status (ever vs never) and pack-years of cigarette smoking, including quadratic terms for continuous variables. Significant covariates $(\mathrm{p}<0.05)$ were included in the linkage models. Only 19 subjects $(3 \%)$ were using antiinflammatory drugs for asthma, so drug usage was not included as a covariate. Multipoint identity-by-descent matrices were estimated by a Markov-Chain Monte Carlo algorithm implemented in the Loki program. ${ }^{21}$ Because of potential misclassification of chronic obstructive pulmonary disease (COPD) as asthma, secondary analyses were performed in non-smokers only by removing the phenotype measurements of current and former smokers, and in smokers-only by removing the phenotypes of non-smokers.

$\log _{10}$ transformed BDR and raw $\mathrm{FEV}_{1}$ measurements had acceptable kurtosis after adjustment for covariates in the final variance component models. Because of residual kurtosis $(>3)$, $\mathrm{FEV}_{1} / \mathrm{FVC}$ measurements were analysed by the t-distribution in SOLAR. Empirical p values for the multipoint LOD scores were estimated by comparing the observed LOD scores with the empirical distribution of LOD scores resulting from 100000 simulations in SOLAR.

One thousand simulations were run in SOLAR to assess our statistical power to detect linkage (LOD scores ranging from $\geqslant 1$ to $\geqslant 3$ ) to a biallelic locus influencing a quantitative trait with heritability ranging from $10 \%$ to $25 \%$ in the Costa Rican pedigrees. These simulations assumed that the trait of interest was influenced by a single quantitative trait locus and that fully informative marker data were available for study subjects.

\section{RESULTS}

\section{Study subjects}

Of the 667 members of the eight participating families, 640 and 624 had spirometric measurements of lung function before and after administration of albuterol, respectively (table 1). There was marked variability among participating families in family size, percentage of former and current smokers and percentage of patients with asthma. As expected in individuals with asthma and their relatives with and without asthma, average values of $\mathrm{FEV}_{1}$ and $\mathrm{FEV}_{1} / \mathrm{FVC}$ were within the normal range. However, post-bronchodilator values were improved.

\section{Analysis of $\mathrm{FEV}_{1}$}

After adjustment for significant covariates (table 2), narrowsense heritability $\left(\mathrm{h}^{2}{ }_{\mathrm{N}}\right.$, the proportion of phenotypic variance explained by genetic factors) for pre-bronchodilator $\mathrm{FEV}_{1}$ was $24.0 \%$ ( SD $6.8 \% ; p=6 \times 10^{-6}$ ). Heritability was similar for postbronchodilator measurements of $\mathrm{FEV}_{1} \quad\left(\mathrm{~h}^{2}{ }_{\mathrm{N}}=23.0 \%\right.$ (SD $\left.6.5 \%), \mathrm{p}=3 \times 10^{-6}\right)$.

Table 2 lists the highest LOD scores from the genome-wide linkage analyses of $\mathrm{FEV}_{1}$ in all subjects, in non-smokers and in 
Table 1 Characteristics of families of children with asthma

\begin{tabular}{|c|c|c|c|c|c|c|c|c|}
\hline \multirow[b]{2}{*}{ Family } & \multirow[b]{2}{*}{ Individuals } & \multirow{2}{*}{$\begin{array}{l}\text { Former and current } \\
\text { smokers* n (\%) }\end{array}$} & \multirow{2}{*}{$\begin{array}{l}\text { Asthmat } \\
\mathrm{n}(\%)\end{array}$} & \multicolumn{2}{|c|}{ Mean (SD) $\mathrm{FEV}_{1}, \%$ predicted $\ddagger$} & \multicolumn{2}{|c|}{$\begin{array}{l}\text { Mean (SD) } \mathrm{FEV}_{1} / \mathrm{FVC}, \% \\
\text { predicted } \neq\end{array}$} & \multirow{2}{*}{ 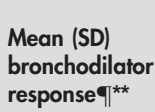 } \\
\hline & & & & Pre-BD§ & Post-BDq & Pre-BD§ & Post-BDq & \\
\hline 1 & 34 & $8(23.5)$ & $12(35.3)$ & $96.1(16.8)$ & $101.1(13.5)$ & $94.5(8.7)$ & $97.2(8.7)$ & $6.6(12.1)$ \\
\hline 2 & 18 & $4(23.5)$ & $7(38.9)$ & $103.9(24.0)$ & $109.2(27.4)$ & $97.8(6.9)$ & $101.2(7.0)$ & $6.1(10.7)$ \\
\hline 3 & 224 & $37(16.5)$ & $56(25.1)$ & $96.6(14.8)$ & $100.3(14.5)$ & $95.8(7.0)$ & $98.7(7.1)$ & $4.3(7.2)$ \\
\hline 4 & 97 & 17 (17.5) & $16(16.5)$ & $102.6(17.4)$ & $107.0(17.0)$ & $96.9(8.0)$ & $99.7(7.8)$ & $5.0(7.3)$ \\
\hline 5 & 8 & $5(62.5)$ & $2(28.6)$ & 100.1 (13.2) & $102.5(13.4)$ & $98.1(7.7)$ & $101.4(5.5)$ & $2.6(6.8)$ \\
\hline 6 & 107 & $10(9.4)$ & $8(7.5)$ & $99.7(16.4)$ & $102.7(16.0)$ & $98.5(6.7)$ & $101.0(5.7)$ & $3.1(7.3)$ \\
\hline 7 & 23 & $9(39.1)$ & $5(21.7)$ & $103.9(12.4)$ & $108.8(11.4)$ & $98.1(5.6)$ & $101.4(4.5)$ & $5.0(5.3)$ \\
\hline 8 & 129 & $12(9.3)$ & $24(18.6)$ & $96.8(13.9)$ & $100.0(13.1)$ & $96.9(8.7)$ & $99.3(7.5)$ & $3.4(7.7)$ \\
\hline All & 640 & 102 (16.0) & $130(20.4)$ & 98.5 (15.8) & $102.3(15.4)$ & $96.8(7.6)$ & 99.5 (7.2) & $4.2(7.7)$ \\
\hline \multicolumn{9}{|c|}{ 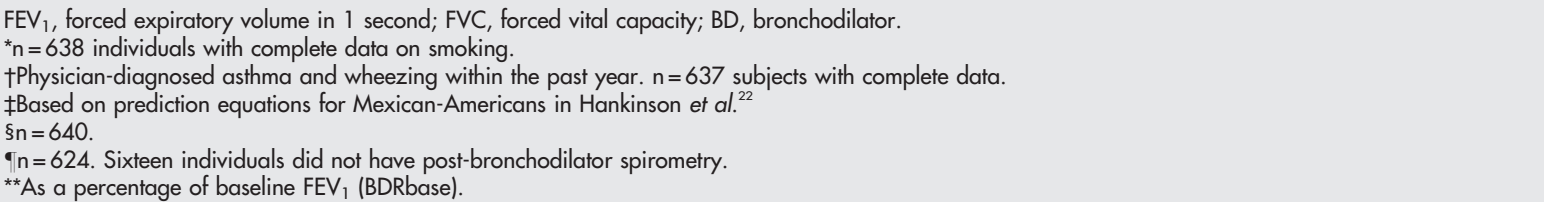 } \\
\hline
\end{tabular}

smokers only; full results are available in Supplementary table 1 (available online at http://thorax.bmj.com/supplemental). In the genome-wide linkage analysis of pre-bronchodilator $\mathrm{FEV}_{1}$ in all subjects, the highest LOD score (1.63 at $127 \mathrm{cM}$ ) was found on chromosome 6q. Four additional genomic regions (chromosomes 4q, 6p, 7p and 16q) showed modest evidence of linkage (LOD $>1$ ) to pre-bronchodilator $\mathrm{FEV}_{1}$. After excluding the phenotypic data of former and current smokers from the analysis, there was only modest evidence of linkage to prebronchodilator $\mathrm{FEV}_{1}$ on chromosomes $4 \mathrm{q}$ and $9 \mathrm{q}$. In smokersonly, the highest LOD score was on chromosome $3 q$ $(\mathrm{LOD}=2.74$ at $24 \mathrm{l} \mathrm{cM})$. Chromosomes $4 \mathrm{q}$ and $8 \mathrm{p}$ also showed suggestive evidence of linkage.

In the genome-wide linkage analysis of post-bronchodilator $\mathrm{FEV}_{1}$ in all subjects, there was suggestive evidence of linkage to chromosome $7 \mathrm{q}(\mathrm{LOD}=2.13 \text { at } 150 \mathrm{cM})^{23}$ and modest evidence of linkage (LOD >1) to chromosomes 1p, 2p, 15q and 16q. Nine additional STR markers were genotyped on chromosome $7 q$, the region with the highest LOD score in the analyses of all subjects. With the additional markers, the LOD score for postbronchodilator $\mathrm{FEV}_{1}$ increased to 2.45 (at $152 \mathrm{cM}$ ) in all subjects (fig 1). Among non-smokers only, chromosomes 1p, 7q and $14 \mathrm{q}$ showed modest evidence of linkage to post-bronchodilator $\mathrm{FEV}_{1}$. After inclusion of additional markers on chromosome $7 \mathrm{q}$, there was suggestive evidence of linkage $(\mathrm{LOD}=2.14$ ) in non-smokers. Chromosomes $2 \mathrm{p}, 4 \mathrm{q}(\mathrm{LOD}=2.66$ at $138 \mathrm{cM})$, $8 \mathrm{p}$ and $14 \mathrm{q}$ all showed suggestive evidence of linkage in smokers only.

\section{Analysis of $\mathrm{FEV}_{1} / \mathrm{FVC}$}

The estimated heritability was $19.9 \%$ (SD $7.8 \% ; \mathrm{p}=2 \times 10^{-4}$ ) for pre-bronchodilator values of $\mathrm{FEV}_{\mathrm{l}} / \mathrm{FVC}$ ratio and $15.4 \%$ (SD $6.6 \% ; \mathrm{p}=0.001)$ for post-bronchodilator values. Table 2 and Supplementary table 2 (available online at http://thorax.bmj. com/supplemental) show the results of the genome-wide linkage analysis of $\mathrm{FEV}_{\mathrm{l}} / \mathrm{FVC}$. In the genome-wide linkage analysis of pre-bronchodilator $\mathrm{FEV}_{1} / \mathrm{FVC}$ in all subjects, the highest LOD score was on chromosome $2 \mathrm{q}$ ( $\mathrm{LOD}=1.53$ at 245 cM). There was also modest evidence of linkage to prebronchodilator $\mathrm{FEV}_{1} / \mathrm{FVC}$ on chromosomes $4 \mathrm{q}$ and $7 \mathrm{q}$. Among non-smokers there was modest evidence of linkage to prebronchodilator $\mathrm{FEV}_{\mathrm{l}} / \mathrm{FVC}$ on chromosomes $2 \mathrm{p}, 3 \mathrm{q}, 4 \mathrm{q}(\mathrm{LOD}=$ 1.50 at $95 \mathrm{cM}), 6 \mathrm{p}, 7 \mathrm{q}$ and 13q. In smokers only the highest LOD score was on chromosome $9 \mathrm{q}(\mathrm{LOD}=1.52$ at $72 \mathrm{cM})$.

For post-bronchodilator measurements of $\mathrm{FEV}_{\mathrm{l}} / \mathrm{FVC}$, the highest LOD score in all subjects was on chromosome $7 \mathrm{p}$ $(\mathrm{LOD}=1.40$ at $74 \mathrm{cM})$. There was also modest evidence of linkage to post-bronchodilator $\mathrm{FEV}_{\mathrm{l}} / \mathrm{FVC}$ on chromosomes $\mathrm{lq}$, $3 \mathrm{p}, 4 \mathrm{q}$ and 20q. Among non-smokers there was modest evidence of linkage to post-bronchodilator $\mathrm{FEV}_{\mathrm{l}} / \mathrm{FVC}$ on chromosomes $2 \mathrm{p}, 3 \mathrm{p}, 4 \mathrm{q}, 5 \mathrm{q}, 6 \mathrm{p}, 7 \mathrm{p}$ and 18q. In smokers only the LOD score of 3.27 on chromosome $5 p$ (49 cM) approached genome-wide significant evidence of linkage. ${ }^{23}$

\section{Analysis of bronchodilator responsiveness}

The three measures of bronchodilator responsiveness $\left(\log _{10}\right.$ transformed) were significantly heritable (BDRbase: $\mathrm{h}^{2}{ }_{\mathrm{N}}=10.5 \%$ (SD

Table 2 Genome-wide linkage analysis for $\mathrm{FEV}_{1}$ and $\mathrm{FEV}_{1} / \mathrm{FVC}$ in all subjects, non-smokers and smokers only

\begin{tabular}{|c|c|c|c|c|c|c|c|}
\hline Phenotype & Bronchodilator & Subjects & Covariates & Chromosome & cM & LOD & p Value \\
\hline \multirow[t]{6}{*}{$\mathrm{FEV}_{1}$} & Pre & All & Age, age ${ }^{2}, h t, h^{2}{ }^{2} w^{2}{ }^{2}$ gender, smoker & 6 & 127 & 1.63 & 0.004 \\
\hline & & Non-smokers & Age, age ${ }^{2}, h t^{\prime} t^{2}, w^{2}{ }^{2}$, gender & 9 & 153 & 1.09 & 0.014 \\
\hline & & Smokers & Age, age ${ }^{2}$, ht, gender & 3 & 241 & 2.74 & $<0.001$ \\
\hline & Post & All & Age, age ${ }^{2}, h t, h^{2}, w^{2}{ }^{2}$, gender & 7 & 150 & 2.13 & 0.002 \\
\hline & & Non-smokers & Age, age ${ }^{2}, h t, h^{2}, w^{2}$, gender & 7 & 150 & 1.73 & 0.003 \\
\hline & & Smokers & Age, age $^{2}$, ht, gender & 4 & 138 & 2.66 & $<0.001$ \\
\hline \multirow[t]{6}{*}{$\mathrm{FEV}_{1} / \mathrm{FVC}$} & Pre & All & Age & 2 & 245 & 1.53 & 0.004 \\
\hline & & Non-smokers & Age, ht & 4 & 95 & 1.50 & 0.004 \\
\hline & & Smokers & Age, age ${ }^{2}$ & 9 & 72 & 1.52 & 0.002 \\
\hline & Post & All & Age, age ${ }^{2}$, ht, wt & 7 & 74 & 1.40 & 0.007 \\
\hline & & Non-smokers & Age, ht, wt & 18 & 117 & 1.46 & 0.006 \\
\hline & & Smokers & Age, age ${ }^{2}$, packs & 5 & 49 & 3.27 & $<0.001$ \\
\hline
\end{tabular}

$\mathrm{FEV}_{1}$, forced expiratory volume in one second; FVC, forced vital capacity; ht, height; smoker, ever smoker; packs, pack-years; wt, weight $\mathrm{Age}^{2}, \mathrm{ht}^{2}$ and $\mathrm{wt}^{2}$ represent the quadratic terms for age, height and weight, respectively.

The maximum LOD score for each analysis is reported. Full results are available in supplementary tables 1 and 2. 


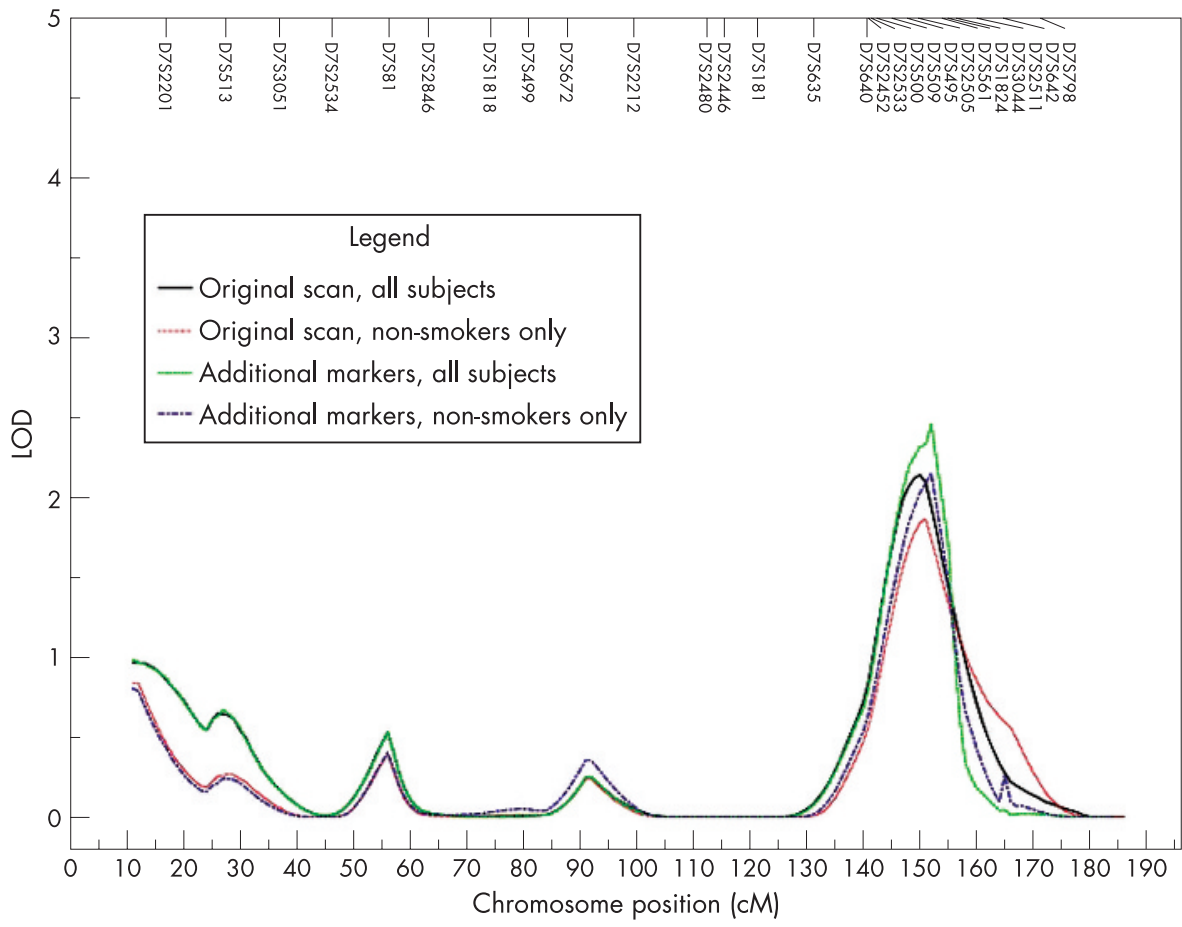

Figure 1 Linkage analysis on chromosome 7 for post-bronchodilator $\mathrm{FEV}_{1}$ in all subjects and in non-smokers only using short tandem repeat (STR) markers from the initial genome scan and including nine additional STR markers.

6.1\%), $\mathrm{p}=0.01$; BDRpred: $\mathrm{h}^{2}{ }_{\mathrm{N}}=10.4 \%(\mathrm{SD} 6.1 \%), \mathrm{p}=0.01$; BDRabs: $\left.h^{2}{ }_{N}=8.0 \% \quad(S D 5.6 \%), p=0.04\right)$, although the heritability estimates were lower than those of the pulmonary function measures. No covariates were significant in the variance component models of the three BDR outcomes in all subjects and in non-smokers. In the genome-wide linkage analysis of BDRbase $\left(\log _{10}\right.$ transformed), the highest LOD score was found on chromosome $4 \mathrm{q}(\mathrm{LOD}=1.26$ at $70 \mathrm{cM}$; table 3 and supplementary table 3 (available online at http:// thorax.bmj.com/supplemental)). A LOD score $>1$ was found in this location in the analysis of BDRpred. In the analyses of BDRpred and BDRabs, the highest LOD scores were found on chromosome 9p at $49 \mathrm{cM}$ (BDRpred: $\mathrm{LOD}=1.25$, BDRabs: LOD $=1.53$ ). Despite the reduced sample size, the LOD scores were increased on chromosomes $4 \mathrm{q}$ and $9 \mathrm{p}$ in analyses restricted to non-smokers only. In non-smokers only, a region on chromosome 10p had LOD scores $>1$ for all three BDR phenotypes. In smokers, regions on chromosomes $12 \mathrm{q}$ and l6q had LOD scores $>1$ for all three BDR measures.

\section{Statistical power}

Our statistical power to detect a LOD score $\geqslant 1$ was $42 \%$ for traits with $\mathrm{h}^{2}{ }_{\mathrm{N}}=10 \%$ (eg, BDRbase) and $98 \%$ for traits with $\mathrm{h}^{2}{ }_{\mathrm{N}}=25 \%$ (eg, pre-bronchodilator $\mathrm{FEV}_{\mathrm{l}}$ ). For LOD scores $\geqslant 2$, our power ranged from $13.6 \%$ for traits with $\mathrm{h}^{2}{ }_{\mathrm{N}}=10 \%$ to $87 \%$ for traits with $\mathrm{h}^{2}{ }_{\mathrm{N}}=25 \%$. Finally, our power to detect a LOD score $\geqslant 3$ ranged from $4 \%$ for traits with $\mathrm{h}^{2}{ }_{\mathrm{N}}=10 \%$ to $67 \%$ for traits with $\mathrm{h}^{2}{ }_{\mathrm{N}}=25 \%$.

\section{DISCUSSION}

In families of schoolchildren with asthma in Costa Rica, we found significant genetic contributions (heritability) to interindividual variation in measures of pulmonary function and BDR. The heritability estimates of $\mathrm{FEV}_{1}$ were similar in magnitude to previous studies, ${ }^{24}$ but the heritabilities of $\mathrm{FEV}_{\mathrm{l}} /$ FVC and BDR were lower than have been reported. ${ }^{7}$ Because of low heritability, our study had limited statistical power to detect linkage to BDR. However, we had adequate statistical power to detect and found genome-wide suggestive evidence of linkage ${ }^{23}$ to post-bronchodilator $\mathrm{FEV}_{1}$, on chromosome $7 \mathrm{q} 34$ 35, which was improved after inclusion of additional STR markers.

Although no significant or suggestive evidence of linkage was found in the other genome-wide linkage analyses in all subjects, we uncovered potential regions of interest, including chromosome $9 p$ for BDR and chromosome $2 q$ for $\mathrm{FEV}_{\mathrm{l}} / \mathrm{FVC}$. Despite a small number of smokers and correspondingly limited power, the evidence for linkage for $\mathrm{FEV}_{1} / \mathrm{FVC}$ (post-bronchodilator) on chromosome $5 \mathrm{p}$ approached genome-wide significance.

Several authors have reported genome-wide linkage analyses for spirometric measures of pulmonary function in families ascertained through probands with asthma; however, the present study is the only genome-wide linkage analysis of $\mathrm{FEV}_{1}$ and $\mathrm{FEV}_{1} / \mathrm{FVC}$ in a Hispanic population. In a study of 2551 members of 533 families in China, Xu et al ${ }^{1}$ found the strongest evidence for linkage to $\mathrm{FEV}_{1}$ on chromosomes $10 \mathrm{p}$ and 22q. In 591 individuals in 202 Australian families, Ferreira et $a l^{2}$ showed suggestive evidence of linkage to $\mathrm{FEV}_{1}$ on chromosomes 5q, 8p, 12q, 17q and 20q and to $\mathrm{FEV}_{1} / \mathrm{FVC}$ on chromosomes 4q, 9q and 12q. Postma et al showed different regions of linkage to $\mathrm{FEV}_{1}$ in genome-wide analyses of all subjects, smokers and non-smokers among 1183 members of 200 Dutch families. They reported genome-wide significant evidence of linkage to $\mathrm{FEV}_{1} / \mathrm{FVC}$ (both pre-bronchodilator and post-bronchodilator) on chromosome 2q.

There have been no previous reports of suggestive or significant evidence of linkage to $\mathrm{FEV}_{1}$ on chromosome 7q. However, the genome-wide linkage analyses of pulmonary function described above were completed in populations of European and Asian descent. A unique aspect of our study is that we were able to recruit large extended pedigrees of children with asthma because of detailed genealogical records and low migration out of the relatively genetically isolated 
Table 3 Genome-wide linkage analysis for bronchodilator responsiveness in all subjects, non-smokers and smokers only

\begin{tabular}{lllclcr}
\hline Phenotype* $^{*}$ & Subjects & Covariates & Chromosome & cM & LOD & p Value \\
\hline BDRbase & All & None & 4 & 70 & 1.26 & 0.008 \\
& Non-smokers & None & 10 & 31 & 1.59 & 0.002 \\
& Smokers & Gender & 16 & 66 & 1.31 & 0.019 \\
BDRpred & All & None & 9 & 49 & 1.25 & 0.007 \\
& Non-smokers & None & 10 & 31 & 1.69 & 0.002 \\
& Smokers & Gender & 16 & 66 & 1.22 & 0.018 \\
BDRabs & All & None & 9 & 49 & 1.53 & 0.003 \\
& Non-smokers & None & 9 & 49 & 1.72 & $<0.001$ \\
& Smokers & Gender & 16 & 66 & 1.60 & 0.012 \\
\hline
\end{tabular}

The maximum LOD score for each analysis is reported. Full results are available in supplementary table 3.

*Definitions of BDR phenotypes'.

$\mathrm{BDRbase}=\left(\mathrm{FEV} V_{\text {post-bronchodilator }}-\mathrm{FEV}_{1 \text { pre-bronchodilator }}\right) / \mathrm{FEV}$ 1 pre-bronchodilator $\times 100 \%$

$\mathrm{BDRpred}=\left(\mathrm{FEV}_{\text {1 post-bronchodilator }}-\mathrm{FEV}_{\text {1 pre-bronchodilator }}\right) / \mathrm{FEV}_{1 \text { predicted }} \times 100 \%$.

$\mathrm{BDRabs}=(\mathrm{FEV}$ 1 post-bronchodilator $-\mathrm{FEV}$ 1 pre-bronchodilator $)$.

All three $B D R$ variables were $\log _{10}$ transformed for analysis.

population of the Central Valley of Costa Rica. Our statistical power to detect linkage to lung function measures may have been increased by inclusion of extended pedigrees (which offer more power for linkage analysis of quantitative traits than sibpair studies with the same sample size $)^{25}$ and by founder effects leading to relatively few susceptibility genes for asthma-related traits in Costa Rica. On the other hand, genetic heterogeneity in determinants of lung function among the Spanish and Amerindian founders of the population of the Central Valley may have hindered our statistical power. Although the characteristics of the Costa Rican population may limit the generalisability of our results, it should be noted that the $G$ protein coupled receptor-154 (GPR154) was first identified as a potential asthma-susceptibility gene in a genetically isolated population in Finland ${ }^{26}$ and then shown to be relevant in other European nations. ${ }^{27}{ }^{28}$ Thus, some of our results may be relevant across ethnic groups and others may be more relevant to Costa Ricans and other Hispanic groups of predominant Spanish and Amerindian ancestry.

Genome-wide linkage analyses of pulmonary function have also been performed in families from the general population ${ }^{24}$ 29-31 and in families of probands with severe, early-onset COPD. ${ }^{32}$ Several of the regions of interest (LOD $\geqslant 1.5)$ in our study are similar to the findings in those studies (table 4), suggesting that some genomic regions are likely to contain genetic variants that influence pulmonary function in normal individuals, in patients with COPD and in those with asthma. Some of these regions may be relevant across different ethnic groups as well. In our analysis, the highest LOD score for $\mathrm{FEV}_{\mathrm{l}} / \mathrm{FVC}$ was found on chromosome 2q. This region overlaps the linkage peaks for $\mathrm{FEV}_{1} / \mathrm{FVC}$ in families from the general population in $\mathrm{Utah}^{31}$ and in families from the Boston Early-Onset COPD Study. ${ }^{32}$ The FEV $_{1} / \mathrm{FVC}$ linkage found in Dutch asthma families is also located on chromosome 2q, but closer to the centromere. ${ }^{3}$

The highest LOD score in any of the genome scans was found for $\mathrm{FEV}_{1} / \mathrm{FVC}$ (post-bronchodilator) on chromosome $5 \mathrm{pl} 3$ in an analysis limited to former and current smokers. Despite the limited sample size, the LOD score of 3.27 approached genomewide significance, ${ }^{23}$ possibly identifying a locus (or loci) for smoking-related air flow obstruction in families with a genetic predisposition to asthma, consistent with the Dutch hypothesis, which proposes a common origin for asthma and COPD. Several cadherin genes (CDH-6, 9 and 10) are located on chromosome $5 \mathrm{pl3}$. E-cadherin $(\mathrm{CDHl})$, another member of the cadherin family, is a cell adhesion molecule involved in epithelial permeability in allergic asthma. ${ }^{34}$ The importance of other cadherin genes in asthma and COPD is unknown.

Although other studies of asthma have analysed both prebronchodilator and post-bronchodilator spirometry, the only previous genome-wide linkage analysis of BDR as a distinct phenotype is from the Boston Early-Onset COPD Study. ${ }^{7}$ An analysis limited to chromosome 12q examined BDR in families from the Childhood Asthma Management Program Study ${ }^{35}$; the present study is the first reported genome-wide linkage analysis of BDR in families of subjects with asthma. Similar to the Boston Early-Onset COPD Study, we found significant heritability of BDR, although the heritability estimates in our asthma families $\left(\mathrm{h}^{2}{ }_{\mathrm{N}}\right.$ range $8.0-10.5 \%$ for the three BDR measures) are lower than those found in the COPD families $\left(\mathrm{h}^{2}{ }_{\mathrm{N}}\right.$ range $\left.10.1-26.3 \%\right)$. As in our study, no significant linkage for BDR measurements was found in the Boston Early-Onset COPD Study, although regions on chromosomes $3 \mathrm{q}$ and $4 \mathrm{q}$ had LOD scores of $\geqslant 1.5$.

The ability to detect linkage to measures of BDR may be limited by the day-to-day variability in BDR that is inherent in

Table 4 Overlapping regions of linkage for pulmonary function phenotypes

\begin{tabular}{|c|c|c|c|c|c|}
\hline \multirow[b]{2}{*}{ Chromosome } & \multicolumn{2}{|l|}{ Present study } & \multicolumn{3}{|l|}{ Previous studies } \\
\hline & Phenotype & $\begin{array}{l}\text { LOD score } \\
\text { (cM) }\end{array}$ & Author, year & Phenotype/Population & LOD score (cM) \\
\hline 2 & $\mathrm{FEV}_{1} / \mathrm{FVC}$, pre-BD & $1.53(245)$ & $\begin{array}{l}\text { Palmer, } 2003^{7} \\
\text { Malhotra, } 2003^{31} \\
\text { Postma, } 2005^{3}\end{array}$ & $\begin{array}{l}\mathrm{FEV}_{1} / \mathrm{FVC} \text {, post-BD/Early-onset COPD } \\
\mathrm{FEV}{ }_{1} / \mathrm{FVC} \text {, pre-BD/General population } \\
\mathrm{FEV}{ }_{1} / \mathrm{FVC} \text {, pre-BD/Asthma }\end{array}$ & $\begin{array}{l}4.42(222) \\
2.36(216-251)^{*} \\
4.92(195)\end{array}$ \\
\hline 4 & $\mathrm{FEV}_{1} / \mathrm{FVC}$, pre-BD & $1.50(95)$ & $\begin{array}{l}\text { Wilk, } 2003^{30} \\
\text { Ferreira, } 2005^{2}\end{array}$ & $\begin{array}{l}\mathrm{FEV}_{1} / \mathrm{FVC} \text {, pre-BD/General population } \\
\mathrm{FEV}_{1} / \mathrm{FVC} \text {, pre-BD/Asthma }\end{array}$ & $\begin{array}{l}1.64(89.3) \\
2.07+(94)\end{array}$ \\
\hline 7 & $\mathrm{FEV}_{1}$, pre-BD & $1.53(11)$ & Bouzigon, $2004^{33}$ & $\mathrm{FEV}_{1} \%$ predicted, pre-BD/Asthma & $2.17(17.7)$ \\
\hline
\end{tabular}

Chromosomal regions with LOD score $\geqslant 1.5$ in the present study (all subjects) and in at least one previous study are shown.

*1-LOD drop support interval.

$\dagger-\log _{10}$ (p Value). 
asthma. It is not clear which definition of BDR is most useful in genetic studies, so we used three commonly accepted measures. ${ }^{7}$ The fact that many of the regions with LOD scores $>1$ were similar across the analyses of two or all three BDR variables implies that these three definitions are likely to reflect the same underlying phenotype. The concordance of results is not perfect, as some regions were found in only one of the analyses of the BDR variables. The heritability estimates for the BDR measures were lower than those of the spirometric traits, although all heritabilities were statistically significant. This may also reduce the ability to detect significant linkage for BDR.

Additionally, as all subjects did not have post-bronchodilator spirometry, the power in the analyses of post-bronchodilator traits and BDR may be reduced. However, this power reduction should be minimal, as only 16 subjects did not complete the post-bronchodilator measurements. Most patients with asthma (especially children) will have pulmonary function test values within the normal range; our study is no exception (table 1). The limited phenotype range may also limit power in genetic studies. Despite this, we were able to find suggestive evidence for linkage to $\mathrm{FEV}_{1}$.

Post-bronchodilator spirometry is less likely to have substantial day-to-day variability in asthma, as the post-bronchodilator values generally reflect underlying lung function. ${ }^{7}$ In our analysis, the strongest linkage evidence was for post-bronchodilator $\mathrm{FEV}_{1}$. However, pre-bronchodilator spirometry may be more variable within an individual subject and may be more reflective of asthma symptoms and severity. Because the analyses of pre-bronchodilator and post-bronchodilator spirometry may yield different information on lung development, asthma severity and asthma susceptibility, we chose to perform genome scans on both pre-bronchodilator and post-bronchodilator phenotypes.

Even though we did not find genome-wide significant evidence of linkage for pulmonary function or BDR, the suggestive evidence of linkage to $\mathrm{FEV}_{1}$ on chromosome $7 \mathrm{q}$ warrants further investigation. Several plausible asthma candidate genes are located in this region, including the $\mathrm{T}$ cell receptor, $\beta$ subunit (TRB@) and endothelial nitric oxide synthase (NOS3). Polymorphisms in NOS3 have been associated with asthma in some studies ${ }^{36}{ }^{37}$ but not in others. ${ }^{38}{ }^{39}$ As in any genetic analysis, our findings may be due to chance or to causal genetic variants. Although our results were adjusted for multiple testing in the setting of a genome-wide linkage analysis of a single phenotype, we did not adjust for testing of multiple traits because of correlation among lung function phenotypes. Because current methods for association studies cannot be used in a small number of extended pedigrees, we plan to assess our findings further by testing for an association between variants in candidate genes on chromosome 7q34-35 and $\mathrm{FEV}_{1}$ in nuclear families of children with asthma in Costa Rica.

\section{ACKNOWLEDGEMENTS}

We thank the participating families for their enthusiastic cooperation, the members of our field team in Costa Rica (Ligia Sanabria, Jenny Vega, Marvin Corrales, Adriana Gonzalez, Raquel Boza, Joaquín Acuña, Laura Rojas, Ana Castillo, Gabriela Ivankovich, Marcia Solano, Herminia Solano) and the staff at McGill University and the Genome Quebec Innovation Centre (Genevieve Geneau, Alexandre Belisle, Corinne Darmon-Zwaig, Frederick Robidoux, David Roquis and Yannick Renaud) and the Channing Laboratory, Brigham and Women's Hospital (Benedict Bodota, Vimala Chompupong, and Elizabeth Bevilacqua).

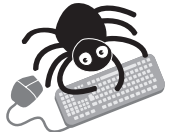

Supplementary tables 1,2 and 3 available online at http://thorax.bmi.com/supplemental

\section{Authors' affiliations}

Craig P Hersh, Stephen L Lake, Catherine Liang, Jody S Sylvia, Ross Lazarus, Barbara J Klanderman, Edwin K Silverman, Juan C Celedón, Channing Laboratory, Department of Medicine, Brigham and Women's Hospital, Boston, Massachusetts, USA

Manuel E Soto-Quirós, Lydiana Avila, Eduardo Fournier, Mitzi Spesny, Division of Pediatric Pulmonology, Hospital Nacional de Niños, San José, Costa Rica

Thomas Hudson, Andrei Verner, McGill University and Genome Quebec Innovation Centre, Montreal, Canada

Nelson B Freimer, Department of Psychiatry, University of California at Los Angeles, Los Angeles, California

Funding: This work was supported by US National Institutes of Health (NIH) grants HL66289, HL04370 and HL073373. Dr Hersh is supported by NIH grant HL080242 and a grant from the Alpha-1 Foundation. The study sponsors had no role in study design, data collection, data analysis, manuscript preparation or submission.

Competing interests: Edwin K Silverman received grant support, consulting fees and honoraria from GlaxoSmithKline for studies of COPD genetics. He has received a speaker fee from Wyeth for a talk on COPD genetics and has also received honoraria from Bayer. None of the other authors declare any competing interests.

\section{REFERENCES}

1 Xu X, Fang Z, Wang B, et al. A genomewide search for quantitative-trait loci underlying asthma. Am J Hum Genet 2001:69:1271-7.

2 Ferreira MA, O'Gorman L, Le Souef $P$, et al. Robust estimation of experimentwise $P$ values applied to a genome scan of multiple asthma traits identifies a new region of significant linkage on chromosome 20q13. Am J Hum Genet 2005;77:1075-85.

3 Postma DS, Meyers DA, Jongepier $\mathrm{H}$, et al. Genomewide screen for pulmonary function in 200 families ascertained for asthma. Am J Respir Crit Care Med 2005; 172:446-52.

4 Hunninghake GM, Weiss ST, Celedon JC. Asthma in Hispanics. Am J Respir Crit Care Med 2006;173:143-63.

5 The Collaborative Study on the Genetics of Asthma (CSGA). A genome-wide search for asthma susceptibility loci in ethnically diverse populations. Nat Genet 1997; 15:389-92

6 Niu T, Rogus JJ, Chen C, et al. Familial aggregation of bronchodilator response: a community-based study. Am J Respir Crit Care Med 2000;162:1833-7.

7 Palmer L, Celedon JC, Chapman HA, et al. Genome-wide linkage analysis of bronchodilator responsiveness and post-bronchodilator spirometric phenotypes in chronic obstructive pulmonary disease. Hum Mol Genet 2003;12:1199-210.

8 The International Study of Asthma and Allergies in Childhood (ISAAC) Steering Committee. Worldwide variations in the prevalence of asthma symptoms: the International Study of Asthma and Allergies in Childhood (ISAAC). Eur Respir International Study
$1998 ; 12: 315-35$.

9 Service S, DeYoung J, Karayiorgou M, et al. Magnitude and distribution of linkage disequilibrium in population isolates and implications for genome-wide association studies. Nat Genet 2006;38:556-60.

10 Melendez C. Conquistadores y Pobladores: Origenes Historico-Sociales de los Costarricenses. San Jose, Costa Rica: Editorial Universidad Estatal a Distancia, 1982

11 Celedon JC, Soto-Quiros ME, Silverman EK, et al. Risk factors for childhood asthma in Costa Rica. Chest 2001;120:785-90.

12 Blumenthal MN, Banks-Schlegel S, Bleecker ER, et al. Collaborative studies on the genetics of asthma-National Heart, Lung and Blood Institute. Clin Exp Allergy 1995;25(Suppl 2):29-32.

13 American Thoracic Society. Standardization of spirometry, 1994 update. Am J Respir Crit Care Med 1995;152:1107-36.

14 Dubovsky J, Sheffield VC, Duyk GM, et al. Sets of short tandem repeat polymorphisms for efficient linkage screening of the human genome. Hum Mol Genet 1995:4:449-52.

15 Dib C, Faure S, Fizames C, et al. A comprehensive genetic map of the human genome based on 5,264 microsatellites. Nature 1996;380:152-4.

16 Kong A, Gudbjartsson DF, Sainz J, et al. A high-resolution recombination map of the human genome. Nat Genet 2002:31:241-7.

17 Epstein MP, Duren WL, Boehnke M. Improved inference of relationship for pairs of individuals. Am J Hum Genet 2000;67:1219-31.

18 O'Connell JR, Weeks DE. PedCheck: a program for identification of genotype incompatibilities in linkage analysis. Am J Hum Genet 1998;63:259-66.

19 Celedon JC, Speizer FE, Drazen JM, et al. Bronchodilator responsiveness and serum total IgE levels in families of probands with severe early-onset COPD. Eur Respir J 1999;14:1009-14.

20 Almasy L, Blangero J. Multipoint quantitative-trait linkage analysis in general pedigrees. Am J Hum Genet 1998;62:1198-211.

21 Heath SC. Markov chain Monte Carlo segregation and linkage analysis for oligogenic models. Am J Hum Genet 1997;61:748-60.

22 Hankinson JL, Odencrantz JR, Fedan KB. Spirometric reference values from a sample of the general U.S. population. Am J Respir Crit Care Med 1999;159:179-87. 
23 Lander E, Kruglyak L. Genetic dissection of complex traits: guidelines for interpreting and reporting linkage results. Nat Genet 1995; 11:241-7.

24 Ober C, Abney M, McPeek MS. The genetic dissection of complex traits in a founder population. Am J Hum Genet 2001;69:1068-79.

25 Williams JT, Blangero J. Power of variance component linkage analysis to detect quantitative trait loci. Ann Hum Genet 1999;63:545-63.

26 Laitinen T, Polvi A, Rydman P, et al. Characterization of a common susceptibility locus for asthma-related traits. Science 2004;304:300-4.

27 Melen E, Bruce S, Doekes G, et al. Haplotypes of $G$ protein-coupled receptor 154 are associated with childhood allergy and asthma. Am J Respir Crit Care Med 2005;171:1089-95.

28 Kormann MS, Carr D, Klopp N, et al. G-Protein-coupled receptor polymorphisms are associated with asthma in a large German population. Am J Respir Crit Care Med 2005;171:1358-62.

29 Joost O, Wilk JB, Cupples LA, et al. Genetic loci influencing lung function: a genome-wide scan in the Framingham Study. Am J Respir Crit Care Med 2002; 165:795-9.

30 Wilk JB, DeStefano AL, Arnett DK, et al. A genome-wide scan of pulmonary function measures in the National Heart, Lung, and Blood Institute Family Heart Study. Am J Respir Crit Care Med 2003:167:1528-33.

31 Malhotra A, Peiffer AP, Ryujin DT, et al. Further evidence for the role of genes on chromosome 2 and chromosome 5 in the inheritance of pulmonary function. Am J Respir Crit Care Med 2003;168:556-61.
32 Silverman EK, Palmer $\sqcup$ Mosley JD et al. Genomewide linkage analysis of quantitative spirometric phenotypes in severe early-onset chronic obstructive pulmonary disease. Am J Hum Genet 2002;70:1229-39.

33 Bouzigon E, Dizier MH, Krahenbuhl C, et al. Clustering patterns of LOD scores for asthma-related phenotypes revealed by a genome-wide screen in 295 French EGEA families. Hum Mol Genet 2004;13:3103-13.

34 Goto Y, Uchida Y, Nomura A, et al. Dislocation of E-cadherin in the airway epithelium during an antigen-induced asthmatic response. Am J Respir Cell Mol Biol 2000;23:712-18.

35 Raby BA, Silverman EK, Lazarus R, et al. Chromosome 12q harbors multiple genetic loci related to asthma and asthma-related phenotypes. Hum Mol Genet 2003; 12:1973-9.

36 Lee YC, Cheon KT, Lee HB, et al. Gene polymorphisms of endothelial nitric oxide synthase and angiotensin-converting enzyme in patients with asthma. Allergy 2000:55:959-63.

37 Yanamandra K, Boggs PB, Thurmon TF, et al. Novel allele of the endothelial nitric oxide synthase gene polymorphism in Caucasian asthmatics. Biochem Biophys Res Commun 2005;335:545-9.

38 Holla LI, Buckova D, Kuhrova V, et al. Prevalence of endothelial nitric oxide synthase gene polymorphisms in patients with atopic asthma. Clin Exp Allergy 2002;32:1193-8.

39 Leung TF, Liu EK, Tang NL, et al. Nitric oxide synthase polymorphisms and asthma phenotypes in Chinese children. Clin Exp Allergy 2005;35:1288-94.

\section{Clinical Evidence-Call for contributors}

Clinical Evidence is a regularly updated evidence-based journal available worldwide both as a paper version and on the internet. Clinical Evidence needs to recruit a number of new contributors. Contributors are healthcare professionals or epidemiologists with experience in evidence-based medicine and the ability to write in a concise and structured way.

Areas for which we are currently seeking contributors:

- Pregnancy and childbirth

- Endocrine disorders

- Palliative care

- Tropical diseases

We are also looking for contributors for existing topics. For full details on what these topics are please visit www.clinicalevidence.com/ceweb/contribute/index.jsp

However, we are always looking for others, so do not let this list discourage you.

Being a contributor involves:

- Selecting from a validated, screened search (performed by in-house Information Specialists) epidemiologically sound studies for inclusion.

- Documenting your decisions about which studies to include on an inclusion and exclusion form, which we keep on file.

- Writing the text to a highly structured template (about 1500-3000 words), using evidence from the final studies chosen, within 8-10 weeks of receiving the literature search.

- Working with Clinical Evidence editors to ensure that the final text meets epidemiological and style standards.

- Updating the text every 12 months using any new, sound evidence that becomes available. The Clinical Evidence in-house team will conduct the searches for contributors; your task is simply to filter out high quality studies and incorporate them in the existing text.

If you would like to become a contributor for Clinical Evidence or require more information about what this involves please send your contact details and a copy of your CV, clearly stating the clinical area you are interested in, to CECommissioning@bmigroup.com.

\section{Call for peer reviewers}

Clinical Evidence also needs to recruit a number of new peer reviewers specifically with an interest in the clinical areas stated above, and also others related to general practice. Peer reviewers are healthcare professionals or epidemiologists with experience in evidence-based medicine. As a peer reviewer you would be asked for your views on the clinical relevance, validity, and accessibility of specific topics within the journal, and their usefulness to the intended audience (international generalists and healthcare professionals, possibly with limited statistical knowledge). Topics are usually 1500-3000 words in length and we would ask you to review between 2-5 topics per year. The peer review process takes place throughout the year, and out turnaround time for each review is ideally 10-14 days.

If you are interested in becoming a peer reviewer for Clinical Evidence, please complete the peer review questionnaire at www.clinicalevidence.com/ceweb/contribute/peerreviewer.jsp 